\title{
Impact of a locomotive engine modernization on fuel consumption
}

\author{
Maciej Andrzejewski ${ }^{1 *}$, Paweł Daszkiewicz ${ }^{1}$, Patryk Urbański ${ }^{1}$, Lukasz Rymaniak ${ }^{2}$, \\ Aleksandra Woch $^{1}$ \\ ${ }^{1}$ Łukasiewicz Research Network - Rail Vehicles Institute „TABOR”, Warszawska 181, \\ 61-005 Poznan, Poland \\ ${ }^{2}$ Poznan University of Technology, Faculty of Civil and Transport Engineering, Institute of Internal \\ Combustion Engines and Drives, 5 M. Skłodowska-Curie Square, 60-965 Poznan, Poland
}

\begin{abstract}
Vehicles used in rail transport are characterized by a long service life, which is caused, among others, by the high cost of their purchase. In Poland, the average age of freight diesel locomotives exceeds 40 years. Increasing the wear and tear of vehicles has an impact on many aspects of machine operation, including environmental pollution. Significant wear and degradation of the powertrain components contributes to the increase in pollutant emissions and fuel consumption, which is closely correlated with the production of carbon dioxide. Modernizations involving the replacement of the drive unit are performed in order to reduce the negative impact of rail vehicles on the environment. The article compares the energy consumption of the ST44 locomotive prior to and after modernization. The older 14D40 two-stroke internal combustion engines were replaced with a more modern engine unit $12 \mathrm{CzN} 26 / 26$. Fuel consumption tests were carried out on a test bench using a OW6300 water resistor.
\end{abstract}

\section{Introduction}

Transport is one of the fastest growing industries in the world. At the same time, it is also characterized by high energy consumption. According to the data, the largest share in the total energy consumption in this sector was road transport (75\%). In the case of air and sea transport, their demand share for energy is approx. $10 \%$ for each. The energy consumed by rail transport was about 2\% (Fig. 1) [1]. Taking into account the amount of transported goods and the energy needed to move them, rail transport is characterized by a relatively high transport efficiency by comparison [2].

\footnotetext{
* Corresponding author: maciej.andrzejewski@tabor.lukasiewicz.gov.pl
} 


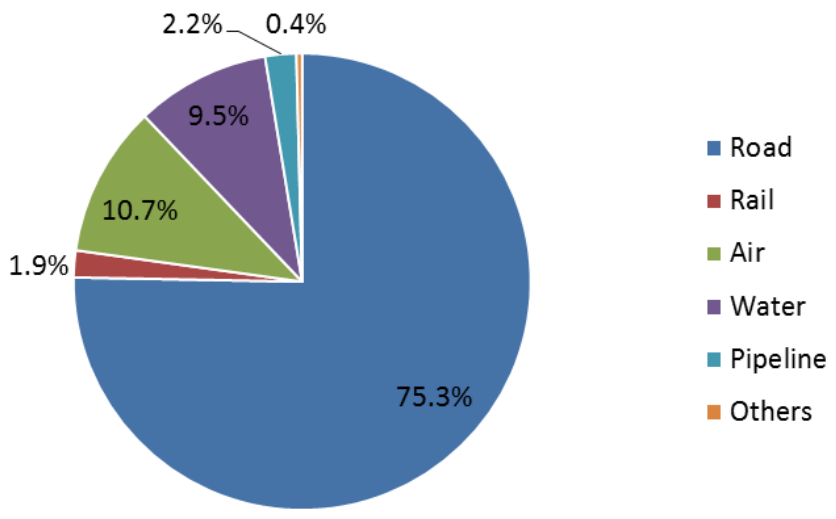

Fig. 1. Share of energy consumption by mode of transport [1].

Various types of fuels [3] are used to power vehicles with internal combustion engines [3]. These are largely based on non-renewable energy sources, which means that they have a negative impact on the natural environment [4-6]. In addition, the demand for to the movement of people and material goods continues to gradually increase along with the economic development of countries/regions of the world. In the years 2000-2017, the level of energy demand in transport worldwide, expressed as tons of crude oil equivalent, almost doubled (Fig. 2). Despite the fact that in North America and Europe the level of energy consumption was mostly stagnant, significant growth took place on the Asian continent, i.e. in China and Japan. Despite the dynamic development of many countries, the observed demand for energy in the railway sector does not change much [7].
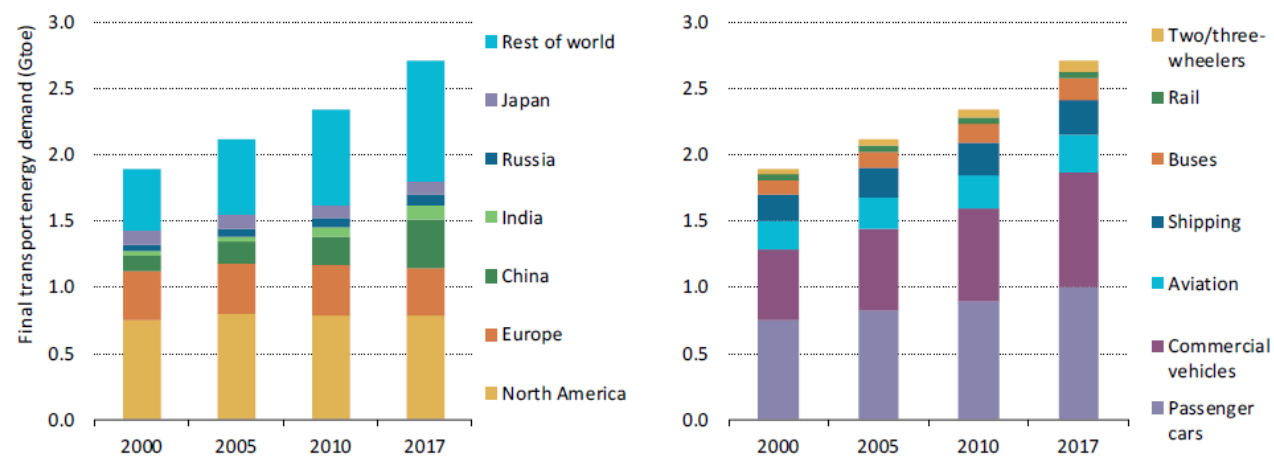

Fig. 2. Transport energy demand in years $2000-2017$ [7].

Due to the high initial purchase costs of locomotives, rolling stock is used over a long period of time. There are 2070 freight diesel locomotives in use in Poland, and their average age is about 40 years [8]. As a result, these vehicles are characterized by a high degree of wear and tear and outdated design solutions. These factors translate directly into increased exhaust emissions and amounts of produced harmful substances. With age, fuel consumption also increases and, consequently, carbon dioxide emissions, lowering the efficiency. The deterioration of engine operating parameters, resulting in the impact of engine units on the environment, necessitates periodic repairs, retrofitting or remotoring, i.e. replacement of the engine unit with a more technologically advanced one which will generate less environmental pollution $[9,10]$. The use of a newer engine in older types 
of diesel locomotives is a procedure that primarily reduces fuel consumption in future operation. Reduction of exhaust emissions of toxic substances and carbon dioxide from rail transport can also be achieved by increasing the reliance on electric multiple units over combustion engine systems (Table 1).

Table 1. Percentage of rail multiple units by the type of energy source in individual European countries expressed as a percentage [11].

\begin{tabular}{|c|c|c|c|c|c|c|}
\hline \multirow[b]{2}{*}{ Country } & \multicolumn{3}{|c|}{ Diesel } & \multicolumn{3}{|c|}{ Electrical energy } \\
\hline & 2003 & 2009 & 2017 & 2003 & 2009 & 2017 \\
\hline Belgium & 12.6 & 12.3 & : & 87.4 & 87.7 & : \\
\hline Bulgaria & 5.1 & 23.9 & : & 94.9 & 76.1 & $:$ \\
\hline Czechia & 81.1 & 73.9 & 71.3 & 18.2 & 26.1 & 28.7 \\
\hline Estonia & 50.8 & 58.2 & 98.9 & 49.2 & 41.8 & 1.1 \\
\hline Greece & 100.0 & 84.4 & 84.8 & $:$ & 15.6 & 15.2 \\
\hline Spain & $:$ & 13.2 & 13.1 & : & 86.8 & 86.9 \\
\hline France & 39.8 & 27.6 & 21.9 & 60.2 & 72.4 & 78.1 \\
\hline Croatia & 72.3 & 79.4 & 70.9 & 27.7 & 20.6 & 29.1 \\
\hline Italy & 53.2 & 55.2 & : & 46.8 & 44.8 & : \\
\hline Latvia & 29.6 & 29.5 & 24.0 & 70.4 & 70.5 & 76.0 \\
\hline Lithuania & 75.0 & 74.1 & 70.7 & 25.0 & 25.9 & 29.3 \\
\hline Luxembourg & : & 5.6 & : & : & 94.4 & : \\
\hline Hungary & 93.4 & 78.2 & 67.3 & 6.6 & 19.6 & 32.7 \\
\hline Austria & : & : & 27.9 & $:$ & $:$ & 72.1 \\
\hline Poland & 2.3 & 11.1 & 12.0 & 97.7 & 88.9 & 88.0 \\
\hline Portugal & $:$ & : & 20.5 & : & : & 79.5 \\
\hline Romania & : & 87.9 & 88.7 & : & 12.1 & 11.3 \\
\hline Slovenia & 63.2 & 64.2 & 64.8 & 36.8 & 35.8 & 35.2 \\
\hline Slovakia & 75.9 & 72.4 & 74.7 & 24.1 & 27.6 & 25.3 \\
\hline Finland & : & 9.7 & 6.8 & 100.0 & 90.3 & 92.4 \\
\hline Sweden & 18.0 & 7.8 & 3.8 & 82.0 & 92.2 & 96.2 \\
\hline North Macedonia & $:$ & 71.4 & 62.5 & $:$ & 28.6 & 37.5 \\
\hline Turkey & 35.8 & 38.5 & 35.0 & 64.2 & 61.5 & 65.0 \\
\hline
\end{tabular}

The use of significantly exploited diesel rail vehicles may have negative both environmental and financial aspects. Taking into account the age of the rolling stock, the tests were carried out to measure the performance of railway engines. The scientific purpose of the work was to analyze the energy consumption of railway diesel engines on the water resistor bed in order to verify the validity of replacing exploited units with new ones. On this basis not only the engine performance parameters, such as power and efficiency, were measured, but also the economic and ecological benefits resulting from this type of activities were estimated and described. During measurements the operating points that are used during approval tests of diesel railway engines were used. 


\section{Method}

The replacement or repair of an internal combustion engine in rail vehicles is beneficial for both environmental and economic reasons $[2,12]$. The reduction of fuel and operating fluids consumption that new engines provide as well as the use of advanced control systems of the drive unit can reduce the costs associated with vehicle maintenance. Limiting the exhaust emission of harmful substances (including carbon dioxide) brings benefits in the environmental aspect.

The aim of the study is to assess and describe the impact of engine modernization of a diesel locomotive on its fuel consumption. The analysis was carried out for the ST44 locomotive model (Fig. 3), in which the modernization included the replacement of the old worn-out 14D40 two-stroke diesel engines with more advanced four-stroke 12CzN26/26 engines manufactured by Kołomna [13]. Four locomotives with inventory numbers 2004, 2018, 2039 and 2055 were designated for the research. Table 2 presents the technical data of the locomotives drive units.

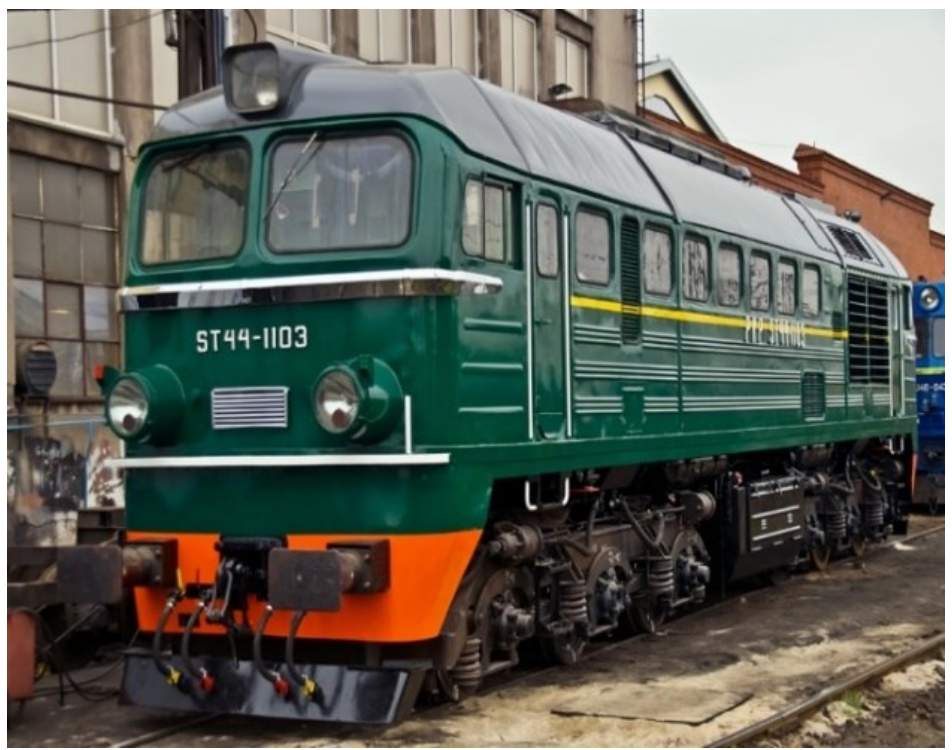

Fig. 3. The ST44 locomotive with an $12 \mathrm{CzN} 26 / 26$ engine [14].

Table 2. Engine technical parameters [12].

\begin{tabular}{|c|c|c|}
\hline Name & engine 14D40 & engine 12CzN26/26 \\
\hline Engine type & Two-stroke & Four-stroke \\
\hline Power $[\mathrm{kW}]$ & 1470 & 1470 \\
\hline Nominal rotational speed of the crankshaft $[\mathrm{rpm}]$ & 750 & 750 \\
\hline Stroke volume $\left[\mathrm{dm}^{3}\right]$ & 150.6 & 150.6 \\
\hline Number and layout of cylinders & $12 / \mathrm{V}\left(45^{\circ}\right)$ & $12 / \mathrm{V}\left(45^{\circ}\right)$ \\
\hline Cylinder diameter $[\mathrm{mm}]$ & 230 & 260 \\
\hline Piston stroke $[\mathrm{mm}]$ & 300 & 260 \\
\hline Engine boosting & Yes & Yes \\
\hline
\end{tabular}


Measurement of fuel consumption was carried out in stationary conditions on a test stand equipped with an OW6300 water resistor (Tab. 3) making it possible to provide load for the generators with low (e.g. ST44 locomotive) and high voltage (e.g. SU46 locomotive). The device converts electricity into heat energy and dissipates it in the tank. The ability to dissipate thermal energy is due to the use of an external electrolyte cooling system, which allows for a continuous load of engines of up to $2000 \mathrm{~kW}$. The resistor box is divided into two parts: the first serves as a reservoir for the electrolyte, and the second is the working chamber with the electrodes. Positive electrodes are connected to the locomotive's generator. Adjusting the resistance of the resistor to the operating parameters of the engine is possible by selecting the number of attached plates. Changing the amount of electrolyte in the working chamber allows for a smooth change of the resulting resistance.

Table 3. Resistor technical parameters [15].

\begin{tabular}{|c|c|}
\hline Resistor type & OW6300 \\
\hline $\begin{array}{c}\text { Continuous power dissipated: } \\
\text { - without electrolyte cooling } \\
\text { - with electrolyte cooling }\end{array}$ & $750 \mathrm{~kW}$ \\
\hline Maximum current & $2000 \mathrm{~kW}$ \\
\hline Continuous current with electrolyte cooling & $6300 \mathrm{~A}$ \\
\hline Continuous current without electrolyte cooling & $2000 \mathrm{~A}$ \\
\hline
\end{tabular}

Fuel consumption was measured at two operating points - when idling and at full engine load. The test took place for a set amount of time during which a certain dose of fuel was consumed. In the case of idling, the mass of fuel consumed was $2 \mathrm{~kg}$, while in the case of operating at full load, used fuel mass was $10 \mathrm{~kg}$. The impact of the replacement of the drive unit on specific performance indicators was assessed, such as hourly and specific fuel consumption, obtained power, engine efficiency.

\section{Results}

The measurement cycles were performed and then repeated twice in order to obtain the most reliable results. The hourly fuel consumption measurement results for specific locomotives while idling were shown in Fig. 4. For the drive system using the 14D40 engine, fuel consumption ranged from $23.6 \mathrm{~kg} / \mathrm{h}$ to $27 \mathrm{~kg} / \mathrm{h}$. In the case of the drive system with the newer $12 \mathrm{CzN} 26 / 26$ engine unit, fuel consumption was found to be significantly lower and ranged between $12.5 \mathrm{~kg} / \mathrm{h}$ and $13.5 \mathrm{~kg} / \mathrm{h}$. Analyzing the average values it can be observed that replacing the engine unit led to the reduction of fuel consumption by $47 \%$ when idling. 


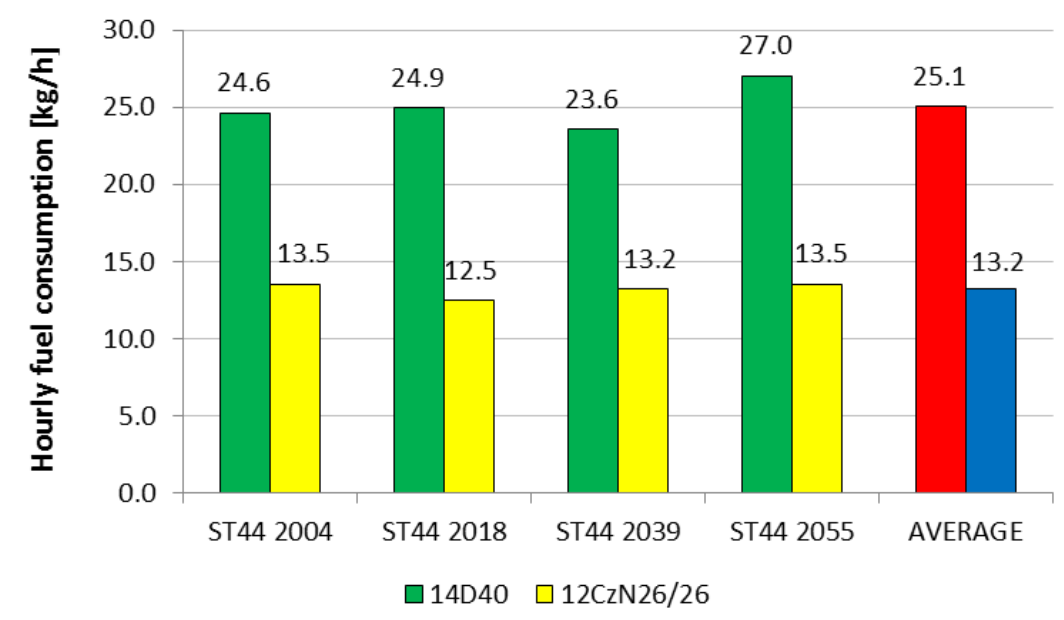

Fig. 4. Comparison of hourly fuel consumption of the tested locomotives during idling.

A significant reduction in fuel consumption for the four-stroke engine was also found for the engines operating at full load. The hourly fuel consumption for a locomotive equipped with the two-stroke engine ranged from $323.7 \mathrm{~kg} / \mathrm{h}$ to $336 \mathrm{~kg} / \mathrm{h}$, while for the locomotives after engine replacement the values ranged from $288.2 \mathrm{~kg} / \mathrm{h}$ to $335.2 \mathrm{~kg} / \mathrm{h}$ (Fig. 5). The average fuel consumption of the drive system with the $12 \mathrm{CzN} 26 / 26$ engine was $4 \%$ lower compared to the older engine design. One outlier was the ST44 locomotive marked 2055, where this trend was reversed. The achieved power of the modernized drive units was on average $59 \mathrm{~kW}$ higher $(5 \%)$ and prior to modernization, which also necessitated higher engine energy demand, thus impacting the observed hourly fuel consumption values (Fig. 6).

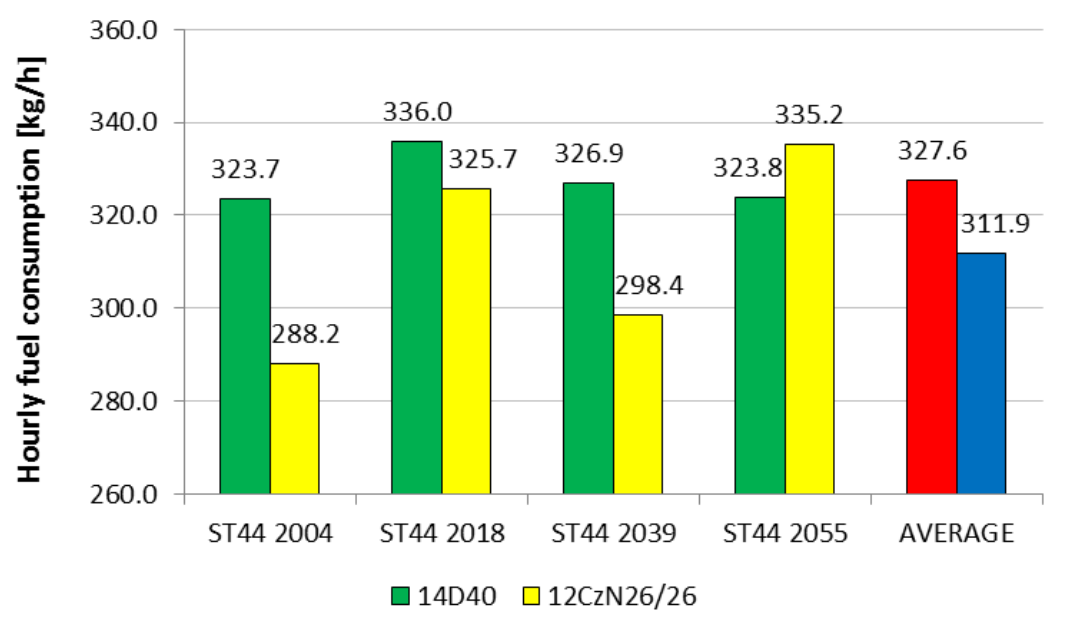

Fig. 5. Comparison of hourly fuel consumption of the tested locomotives for engines working at full load. 


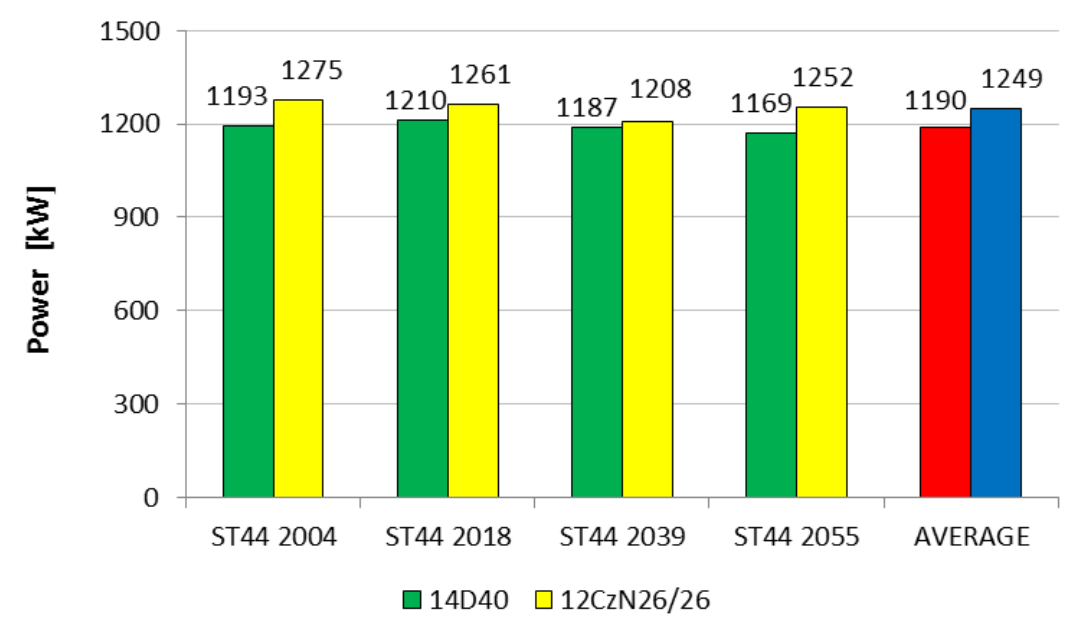

Fig. 6. The measured power output of the tested locomotives for engines working at full load.

Based on the recorded data, the gross and net specific fuel consumption values were calculated for the engines operating at full load (Fig. 7, Fig. 8). The gross specific fuel consumption was related to the entire drive system, i.e. the internal combustion engine with the generator set. For the newer design, it ranged from $226.1 \mathrm{~g} / \mathrm{kWh}$ to $267.7 \mathrm{~g} / \mathrm{kWh}$. Whereas the net specific fuel consumption concerned only the internal combustion engine. The achieved values for the net fuel consumption ranged from $209.6 \mathrm{~g} / \mathrm{kWh}$ to $247.9 \mathrm{~g} / \mathrm{kWh}$. Before modernization, the locomotives had gross specific fuel consumption ranging from $271.3 \mathrm{~g} / \mathrm{kWh}$ to $277.6 \mathrm{~g} / \mathrm{kWh}$. The net fuel consumption vales ranged from $250.3 \mathrm{~g} / \mathrm{kWh}$ to $256.4 \mathrm{~g} / \mathrm{kWh}$. In relative terms the obtained values indicate, that the locomotives with the $12 \mathrm{CzN} 26 / 26$ engine achieved lower specific fuel consumption on average by $9.3 \%$ (gross) and $9 \%$ (net).

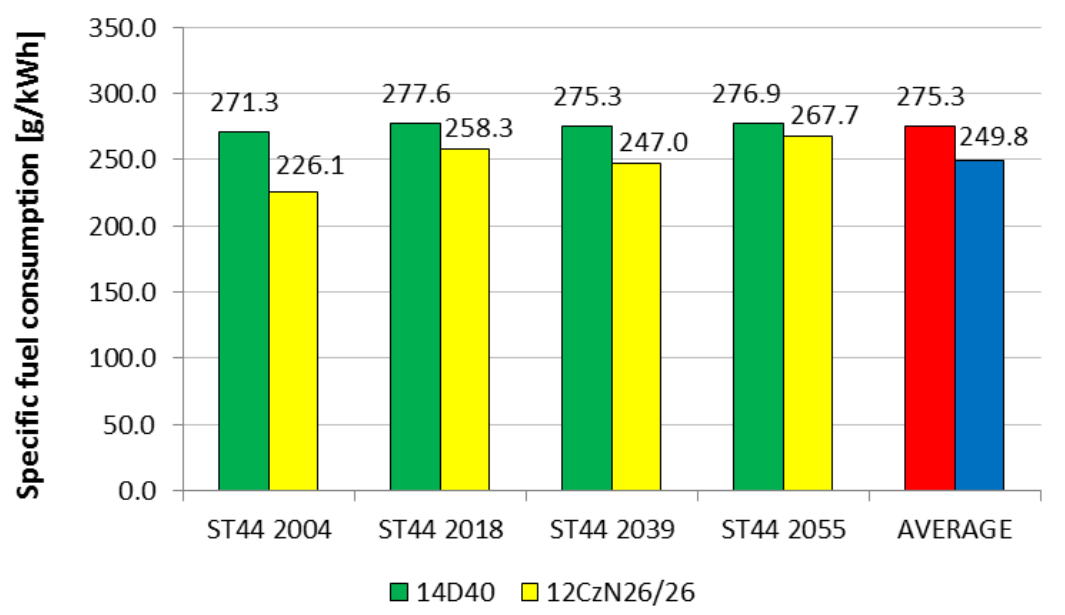

Fig. 7. Comparison of gross specific fuel consumption of the tested locomotives at full engine load. 


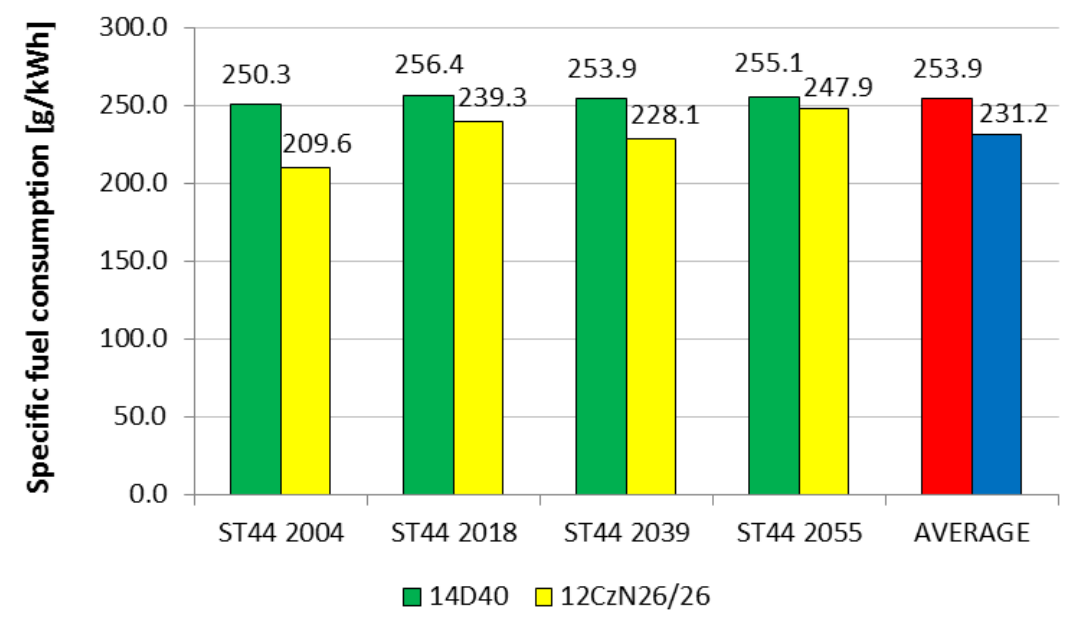

Fig. 8. Comparison of net specific fuel consumption of the tested locomotives at full engine load.

The efficiency of the drive systems was calculated based on the power generated and fuel consumption data (Fig. 9). Drive systems with the old generation two-stroke engines were characterized by efficiency reaching a maximum value of $31 \%$. Replacing the engine in each of the locomotives improved the overall drive system efficiency. The drive systems with the $12 \mathrm{CzN} 26 / 26$ four-stroke engines achieved a maximum efficiency of $37.2 \%$. The modernization improved the efficiency of the considered locomotives by about $3 \%$ on average.

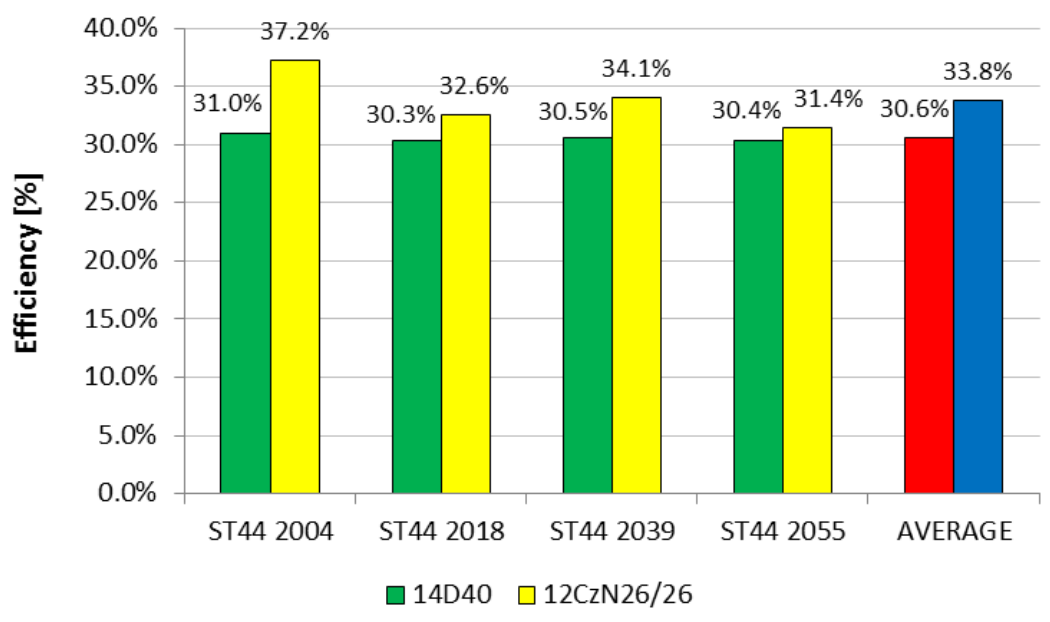

Fig. 9. Comparison of the drive system efficiency at full engine load for individual locomotives.

\section{Conclusions}

The aim of the stationary ST44 diesel locomotive tests carried out on a water resistor was to analyze the impact of vehicle remotoring on the measured fuel consumption. The obtained results show that the replacement of the 14D40 two-stroke engine unit, which was characterized by a significant degree of wear and tear, with the newer 
$12 \mathrm{CzN} 26 / 26$ four-stroke engine unit improved parameters related to fuel consumption, efficiency and generated power. For the no-load idle operation, the hourly consumption for the new engines was almost half of the consumption for the older generation engines. Knowing the time distribution of the engine operating parameters for individual locomotives, in which the share of idling time tends to be significant [16], it can be assumed that the reduction of hourly fuel consumption at engine idle could reduce the fuel costs by up to $50 \%$.

In the case of tests carried out for engine operation at full load, the engine replacement reduced the average hourly fuel consumption by approximately 4\%. Most significantly the gross specific fuel consumption was reduced by approximately $9.3 \%$. Moreover, the new engine unit operated at full load with higher efficiency than the worn-out 14D40 engine.

The remotoring of rail vehicles can result in reducing the fuel consumption, improving performance indicators, reducing engine exhaust emissions, as well as reducing the vehicle operating costs, which is a desirable feature for modernized locomotives that are expected to be used by railway carriers for many years afterwards. Reducing fuel consumption also translates into the reduction of carbon dioxide emissions to the atmosphere, which is largely responsible for the greenhouse effect. Due to the newer solutions used in the fuel supply system and the engine operation control system, as well as the materials used in the $12 \mathrm{CzN} 26 / 26$ engine, the exhaust emission of harmful compounds was also reduced. For this reason, the replacement of drive units in diesel locomotives can be seen as beneficial not only in terms of their economy, but also ecology. However, it should be noted that due to constructional reasons, remotorization is vehicle specific, and in some cases impossible to implement or requires significant financial resources, which may result in such an investment becoming economically unprofitable depending on the vehicles and engines involved.

\section{References}

1. UIC, IEA., Railway handbook 2017: Energy consumption and CO2 emissions. International Energy Agency (IEA) and International Union of Railways (UIC) (2017)

2. M. Andrzejewski, P. Daszkiewicz, Ł. Rymaniak, J. Merkisz, M. Kamińska, Aut.: Tech. Eks. Sys. Trans. 19, 12 (2018)

3. J. Merkisz, D. Gallas, M. Siedlecki, N. Szymlet, B. Sokolnicka, E3S Web of Conf. EDP Scien. 100 (2019)

4. Ł. Rymaniak, P. Lijewski, M. Kamińska, P. Fuć, B. Kurc, M. Siedlecki, T. Kalociński, A. Jagielski, Comp. and Elec. in Agr. 173 (2020)

5. Ł. Rymaniak, P. Fuć, P. Lijewski, M. Kamińska, P. Daszkiewicz, A. Ziółkowski, Arch. of Trans., 52, 4 (2019)

6. P. Lijewski, N. Szymlet, Ł. Rymaniak, B. Sokolnicka, A. Domowicz, E3S Web of Conf. EDP Scien. 100, p. 00047 (2019)

7. Birol, F. The Future of Rail Opportunities for Energy and the Environment. International Energy Agency (IEA), 20-22, France (2019)

8. Potencjal taborowy, Trendy i prognozy - UTK (2020)

9. Z. Marciniak, TTS Tech. Trans. Szyn. 15, 23-37 (2009)

10. Z. Marciniak, TTS Tech. Trans. Szyn. 13, 64-78 (2007)

11. Transport equipment statistics - Eurostat (2019) - internet website

12. W. Stawecki, Z. Marciniak, I. Pielecha, J. Pielecha, Comb. Eng. 53, 48-58 (2014) 
13. M. Lewandowski, Silniki spalinowe pojazdów szynowych. Wyd. Kom. i Łącz. Warsaw, Poland (2018)

14. M. Andrzejewski, P. Daszkiewicz, J. Merkisz, W. Stawecki, D. Gallas, Poj. Szyn. 3, 11-17 (2018)

15. A. Erd, TTS Tech. Trans. Szyn. 7, 49-56 (2000)

16. Ł. Rymaniak, P. Daszkiewicz, J. Merkisz, Y. V. Bolzhelarskyi, AIP Conf. Proc., AIP Publ. LLC 2078, p. 020053 (2019) 